\title{
Investigation of Surface Quality of CoCrMo Alloy Used in the Tibial Component of the Knee Prosthesis According to the Methods of Turning and Turning- Grinding
}

\author{
Erkan BAHÇE ${ }^{1 *}$, Mehmet Sami GÜLER ${ }^{2}$, Ender EMİR ${ }^{3}$ \\ ${ }^{1}$ Department of Mechanical Engineering, Inonu University, Malatya, Turkey \\ ${ }^{2}$ Department of Machinery and Metal Technologies Vocational School of Technical Science, Ordu University, Ordu, Turkey \\ ${ }^{3}$ Department of Mechanical Engineering, Inonu University, Malatya, Turkey
}

crossref http://dx.doi.org/10.5755/j01.ms.26.1.21729

Received 28 September 2018; accepted 15 December 2018

\begin{abstract}
CoCrMo alloys, which are well-known Co-based biomedical alloys, have many different types of surface integrity problems reported in literature. Residual stresses, white layer formation and work hardening layers are some those, matters which occur as a microstructural alteration during machining. Therefore, such problems should be solved and surface quality of end products should be improved. In this paper, the surface quality of CoCrMo alloy used in tibial component of the knee prosthesis produced by means of turning was investigated. An improvement was suggested and discussed for the improvement in their machinability with the developed turning-grinding method. Finite element analyses were also carried out to calculate temperature and thermal stresses distribution between the tool and the tibial component. The results showed that many parameters such as cutting speed, feed rate, depth of cut, tool geometry, and tool wear affect the surface quality of workpieces of CoCrMo alloy. In the turning-grinding method, the machining time is reduced by about six times compared to machining only method. The EDX analysis performed on the surface after machining showed that metal diffusion occurred from tool to the tibial component.

Keywords: CoCrMo alloy, machinability, tibial component, turning-grinding method.
\end{abstract}

\section{INTRODUCTION}

Co-based alloys have been used extensively as biomaterials because of their high wear, temperature, and corrosion resistance. Especially, it is widely used in merging of broken bone parts, knee and hip bone prosthesis. There are basically two types of biocompatible Co-based metallic alloys. The first one is the CoCrMo alloy which is produced by casting, and the second one is the CoCrNiMo alloy, which is produced by hot-rolling. In Co-based alloys, Mo improves the mechanical properties by providing a finegrained structure while, $\mathrm{Cr}$ increases the strength by making solid solution. If forming of the CoCrMo alloy is with high geometric tolerance and surface precision, the chip removal step is carried out. Nonetheless, machining of CoCrMo alloys is difficult as in the cases of high-strength nickelbased super alloys and titanium alloys. Such alloys increase tool wear, decrease surface integrity and considerably affect the production performance.

There are several studies on the chip removal processes of Co-based alloys in literature [1-7]. The effect of cutting parameters on the tool wear was investigated by means of turning or milling, and their effects on surface integrity were also investigated in these studies. Some of these studies investigated the effects of tool materials, tool geometry and tool coating on tool wear $[1-3,5,6]$. Other studies examined other properties such as surface damage, surface roughness, residual stresses, and changes in microstructure of Co-based alloy parts [3-6]. Bordin et al. [1] studied the machinability of CoCrMo alloys produced by forging and electron beam melting. In that study, they performed chip removal process at different feed rates and cutting speeds and took roughness and microhardness measurements on machined surface. They observed that the surface roughness decreased with increasing cutting speed and decreasing the feed rate in both methods. It was also observed that the hardness of machined surface increased with increasing the cutting speed. Bordin et al. [2] investigated the effect of different cutting speed and feed rate on the surface integrity of the CoCrMo alloy with dry turning. It was reported that surface roughness increased with reducing cutting speed. They also observed the adherent chips, rupture, and grooves on the surfaces. Karpuschewski et al. [3] studied the effect of tool geometry on the tool life and flank wear in machining of femoral heads during machining of the CoCrMO alloy. They machined the alloy with single feed rate and cutting depth. They stated it was possible to machine the CoCrMo alloy with the correct ceramic tool. They also indicated that the tool life was shortened with increasing the cutting speed especially with cutting tools having different cutting-edge geometries. Shokrani et al. [4] studied the high speed turning of cobalt-chromium alloys by cooling to low temperatures of $-197{ }^{\circ} \mathrm{C}$. They observed decreases in surface roughness values obtained after machining. Song et al. [5] machined the CoCrMo alloy using the elliptical vibration cutting method. Based on experimental results, elliptical vibration cutting performance was found to be superior than normal diamond cutting without tool

\footnotetext{
* Corresponding author. Tel.: +90-532-320-7845; fax: +90-422-341-0046

E-mail address: : erkan.bahce@inonu.edu.tr (E. Bahçe)
} 
vibration. Bruschi et al. [6] took surface roughness and microhardness measurements during CoCrMo turning conducted at different feed rate and cutting speeds using cooling fluid. They observed a decrease in surface roughness due to the increase of cutting speed and an increase in surface roughness due to the increase of feed rate. On the other hand, the hardness of the alloy surface increased with the increasing the cutting speed and feed rate.

There are also studies used statistical methods aiming to determine the best machining conditions. Jagtap et al. [7] conducted a comparative analysis of the cutting forces during precision-turning of CoCrMo bio-implant alloys in dry and wet machining processes. They prepared experimental set with three cutting depths, feed rates and cutting speeds and used three different tools made of ceramic, carbide and $\mathrm{CBN}$ materials.

In the light of existing literature, it can be concluded that the turning process is widely used in machining the tibial component of total knee prosthesis after casting of CoCrMo alloy. However, the CoCrMo alloys have problems in turning process such as requirement of high cutting forces, knocking, vibration and severe tool wear due to their high strength. Such problems increase both manufacturing cost and manufacturing time. Therefore, the main purpose of the present study is to minimize these problems and increase the surface integrity and quality by applying turning-grinding method.

\section{MATERIALS AND WORK METHOD}

\subsection{Materials}

CoCrMo alloy as extensively prefered material in the tibial component of the knee prosthesis was selected as the test material for current this study (Fig. 1). The tibial component producing in different sizes are subjected to casting, machining and polishing before the final shape (Fig. $1 \mathrm{~b}$ ). The areas in red colour indicate the parts to be removed from the tibial composite (Fig. 1 a). The chemical and mechanical properties of the alloy used are given in Table 1 and Table 2, respectively.

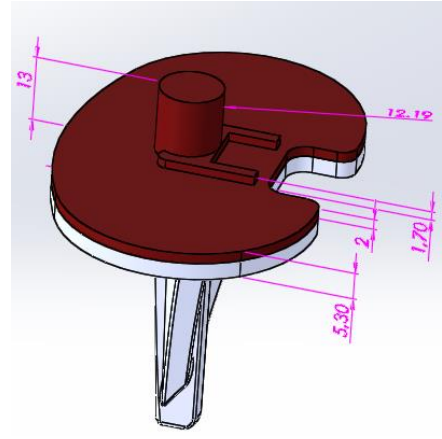

a

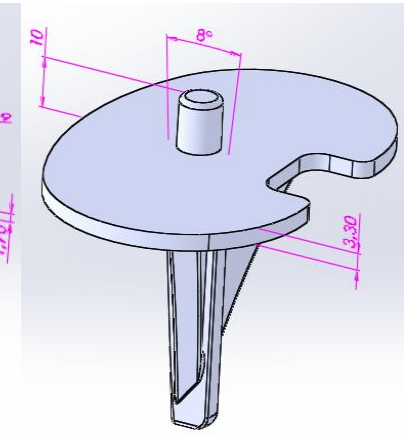

b
Fig. 1. CAD model of the tibial component: a-after casting (the tibial machine part is shown in red); $b$-after machining

\subsection{Work method}

Two different methods were applied for chip removal to achieve the desired geometric tolerance and surface precision of the tibial component made of cast CoCrMo alloy.
Table 1. Chemical composition of the CoCrMo material used in tibial component

\begin{tabular}{|c|c|c|c|c|c|c|c|}
\hline \multicolumn{7}{|c|}{ Element, wt.\% } \\
\hline $\mathrm{Cr}$ & $\mathrm{Mo}$ & $\mathrm{C}$ & $\mathrm{Fe}$ & $\mathrm{Mn}$ & $\mathrm{Si}$ & $\mathrm{Ni}$ & $\mathrm{Co}$ \\
\hline 27.30 & 5.96 & 0.057 & 0.37 & 0.62 & 0.67 & 0.22 & Balance \\
\hline
\end{tabular}

Table 2. Mechanical properties of CoCrMo alloy used in tibial component

\begin{tabular}{|l|c|}
\hline Young's modulus, GPa & 220.0 \\
\hline Poisson ratio, $v$ & 0.29 \\
\hline Hardness, HRC & 35.0 \\
\hline Elongation, \% & 14.0 \\
\hline Ultimate tensile strength, MPa & 1020.0 \\
\hline Yield Strength, MPa & 600.0 \\
\hline
\end{tabular}

The first is the universal turning method (Fig. 2 a), which is the preferred method in the present case. This method was performed in two steps as rough and finish machining, and feed rate and cutting speed values were controlled parameters for the process (Table 3). These parameters were determined based on the literature and initial studies. The cutting tool used in the turning process was chosen considering the existing literature into account and manufacturing methods (Table 4). Boron oil was used as cooling fluid in the turning process.

Table 3. Machining parameters of CoCrMo Alloy for turning

\begin{tabular}{|c|c|c|}
\hline Machining type & Feed rate, $\mathrm{mm} / \mathrm{rev}$ & Revolution, \\
\hline Rough machining & 0.2 & 150 \\
\hline \multirow{3}{*}{ Finish machining } & 0.08 & $125-150-175$ \\
\cline { 2 - 3 } & 0.09 & $125-150-175$ \\
\cline { 2 - 3 } & 0.1 & $125-150-175$ \\
\hline
\end{tabular}

Table 4. Cutting tool material and geometrical parameters

\begin{tabular}{|l|l|l|}
\hline & \multicolumn{1}{|c|}{ Rough pass } & \multicolumn{1}{c|}{ Finish pass } \\
\hline Apex angle, ${ }^{\circ}$ & 55 & 55 \\
\hline Radius, mm & 0.8 & 0.4 \\
\hline Material & Tungsten carbide & Tungsten carbide \\
\hline
\end{tabular}

The second applied machining method is the turninggrinding which is different from the existing literature. In this method, the chip removal process was carried out with a new design grinding wheel with spindle speed of $8500 \mathrm{rpm}$ feed rate $0.1 \mathrm{~mm} / \mathrm{rev}$ connected to the tool holder instead of the cutting tool in CNC lathe (Fig. 2). The chip removal image is given in Fig. 2 b.

Turning-grinding process, was carried out in two steps as, rough and finish machining similar to the chip removal process. Machining parameters were not changed because of the constant revolution and feed rate of the grinding wheel in coarse and fine passes. The grinding wheel properties used in this process are given in Table 5. Cooling fluid was not used in this process.

The offset of the tools was selected to be $0.2 \mathrm{~mm}$ in both methods. The polishing process was applied as final process by using polishing cloth and paste.

Four types of experimental results were collected: tool wear, surface roughness, micro hardness, and surface 
defects in order to evaluate the surface quality of the tibial component.

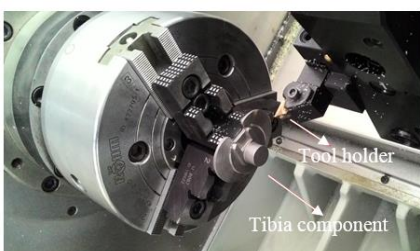

a

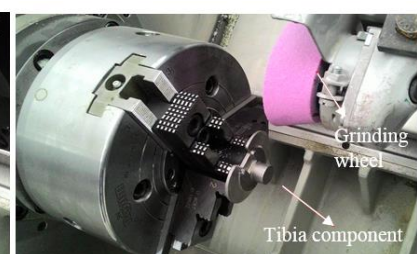

b
Fig. 2. Chip removal process of tibial component: a-the turning method; $b$ - the turning-grinding method

Table 5. Grinding wheel parameters

\begin{tabular}{|l|l|}
\hline Grain type & Index \\
\hline High-purity aluminum oxied & EKR \\
\hline Grain number & 60 \\
\hline Hardness degree & K \\
\hline Texture characteristic number mid & 6 \\
\hline Ceramic binding & V \\
\hline
\end{tabular}

The roughness of machined surface was measured by MITUTOYO SJ-210 with a measurement accuracy of $0.001 \mu \mathrm{m}$ (Fig. $3 \mathrm{a}$ ). Roughness measurement (Ra) was obtained with a taking cut-off distance of $0.8 \mathrm{~mm}$ and probe advance rate of $0.5 \mathrm{~mm} / \mathrm{sec}$. The tibial component was divided into four different regions for roughness measurements as shown in Fig. 3 b, and measurement of average roughness values was carried out around circular lines formed towards the machining centre. Roughness values were reported by taking averages of five measurements from circular lines in order to increase the accuracy of measurement.

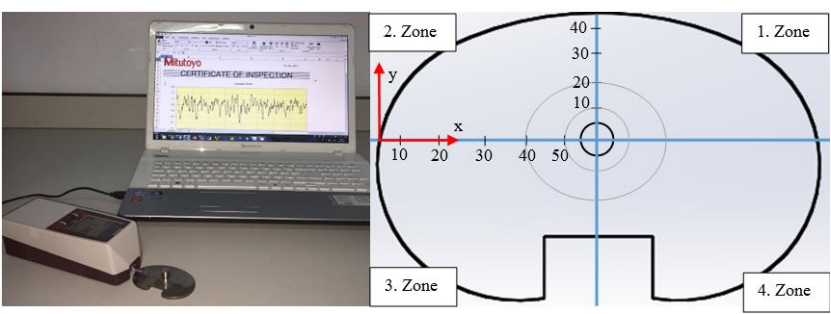

a

b

Fig. 3. Roughness measurements of the tibial component: $\mathrm{a}$-roughness measurement system; $\mathrm{b}$ - measurement zones

Plastic deformation occurs in the machining surfaces during chip removal processes. Thus, it is important to examine the change in the hardness. For this purpose, a micro-hardness tester (Shimadzu HMV-G) was used to measure microhardness from the centre of the tibial surface to the outside in four different directions $0^{\circ}, 45^{\circ}, 135^{\circ}$, and $180^{\circ}$ as in Fig. 4. The machined surfaces were examined by means of a scanning electron microscopy (SEM).

\section{RESULTS AND DISCUSSION}

\subsection{Surface roughness}

The variations of average surface roughness values $(R \mathrm{a})$ obtained from the tibia surfaces machined by turning are shown in Fig. 5.

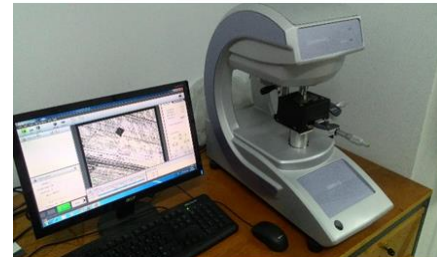

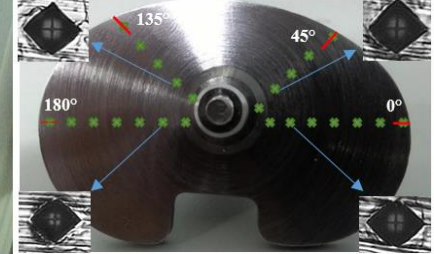

$\mathrm{b}$
Fig. 4. Hardness measurement: a-hardness measurement system; $\mathrm{b}$-the locations and directions where the hardness measurements obtained

The roughness values for $n=100 \mathrm{rev} / \mathrm{min}$, $\mathrm{n}=125 \mathrm{rev} / \mathrm{min}$ and $\mathrm{n}=175 \mathrm{rev} / \mathrm{min}$ were also measured in the experiment. Fig. 5 a was recorded for only $\mathrm{n}=150 \mathrm{rev} / \mathrm{min}$, and the other measured values were not included in Fig. 5 a to avoid complexity of curves and provide a better understanding, since the measured values obtained for other rev/min values were very close to one measured for $n=150 \mathrm{rev} / \mathrm{min}$. Similar case is valid for Fig. $5 \mathrm{~b}$ for the feed rate value of $0.1 \mathrm{~mm} / \mathrm{rev}$.
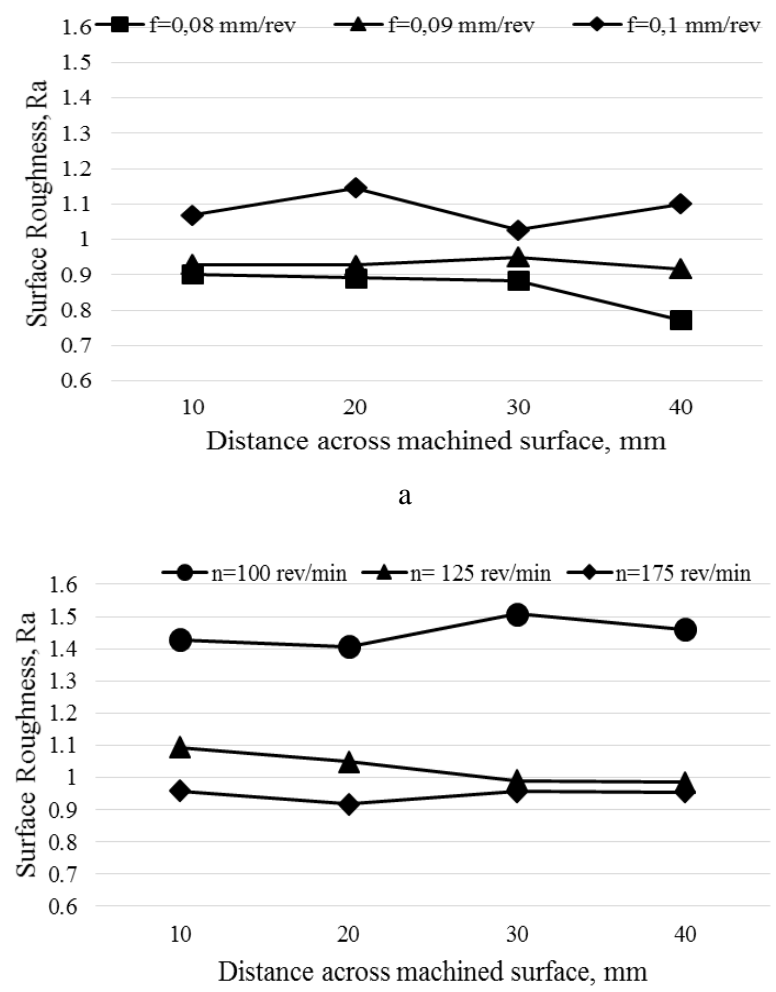

b

Fig. 5. The variation of surface roughness in turning process according to the machining parameters: a-in $150 \mathrm{rpm}$; $\mathrm{b}$-at different for to $0.1 \mathrm{~mm} / \mathrm{rev}$

From the graphs, the $R$ a value decreases with increasing cutting speed, whereas it increases with increasing feed rate as expected in traditional chip removal operations (Fig. 5). According to the results, while the highest roughness value is about $1.509 \mu \mathrm{m}$ at $100 \mathrm{rpm}$, and $0.1 \mathrm{~mm} / \mathrm{rev}$, the lowest roughness value is obtained as $0.772 \mu \mathrm{m}$ at $150 \mathrm{rpm}$, $0.08 \mathrm{~mm} / \mathrm{rev}$. Increasing feed rate value causes an increase in the amount of chip removal per unit time and increases in the cutting forces as mentioned in the literature [8]. Increasing the load level on the tool adversely affects the surface quality, and the values of the average surface 
roughness increases with increasing feed rates, as expected (Fig. 5 a). Similarly, the surface temperature increases with increasing cutting speed due to the increase in heat energy that facilitates plastic deformation and chip flow, this results improvement in surface quality in the literature [9]. When Fig. 5 is examined, it can be seen that $R$ a values up to $125 \mathrm{rev} / \mathrm{min}$ are in a very narrow range, and then, there is a significant difference in roughness values.

The $R$ a values obtained on the tibia surfaces manufactured by turning-grinding method, on the other hand, is given in Fig. 6. At the same time, the average of the roughness values obtained from the turning method is included to be able to compare the results. While the highest and the lowest roughness values are obtained as $0.701 \mu \mathrm{m}$, and $0.647 \mu \mathrm{m}$ in the turning-grinding method along with constant revolution and feed rate. The turning-grinding method has a positive effect on the surface quality as well as it improves the wear resistance of grinding wheel. This can be attributed to the fact that the low friction coefficient of the grinding material which influences the surface quality favourably by facilitating the chip flow [10, 11]. Additionally, the force acting on abrasive grains causes to break off the grains from the grinding disc in the grinding process. The availability of the new sharp-edged broken abrasive grains prevents the increase of unstable forces during the chip removal process.

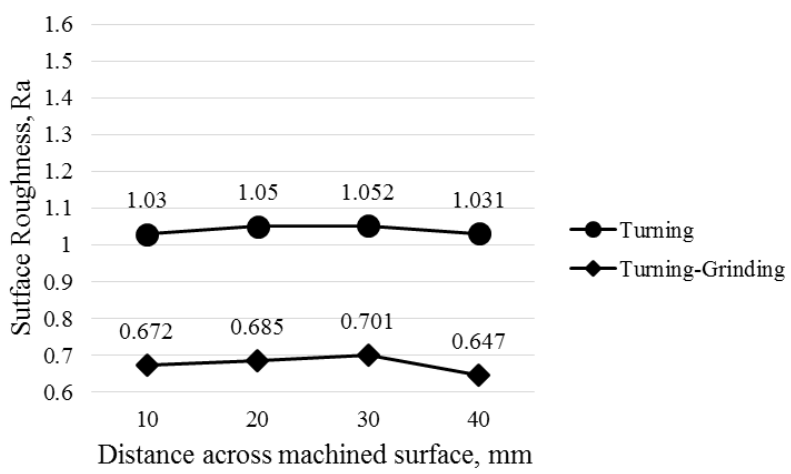

Fig. 6. Comparison of surface roughness value between turning and turning-grinding processes

When the two methods employed in current study are compared, while the chip removal process can not be realized in high speeds during the turning method, high speeds in the removal process are reached during grinding turning method. In order to reach high cutting speed, e.g. $8500 \mathrm{rpm}$, in the turning method, it is necessary to reduce the cutting thickness to $1 \mu \mathrm{m}$, but this results in an increase in processing time and manufacturing costs. When the revolutions exceed $200 \mathrm{rpm}$, wear on the cutting tool increases and this result in excessive wear of the tool. To analyse these conditions, the tool cutting surfaces were also examined in terms of machining time and the results are given in Fig. 7.

When the graph is examined, the machining parameters seem to be important for tool wear if the material pairs are the same. In addition, temperature is one of the most important factors in this situation. Increasing cutting speed reduces the tool life as it increases wear. Therefore, machining temperature is the most important factor in turning method, and it is the most important reason why the spindle speed could not be increased. This finding is corresponding well with the results available in literature $[10,12]$.

When Fig. 7 is examined, the machining time of a tibial component is about 45 minutes in turning method, while this time is only about 7 minutes in turning-grinding method. In the experiments conducted, it was observed that one cutting tool was used for one tibial component during rough machining in the turning method, while one cutting tool was used for two tibial components during finish machining. In the turning-grinding method, 24 tibial components were machined in both rough and finish machining.

As a result, better surface qualities were obtained by turning-grinding method compared to conventional turning. This allows the cutting process to be continued with the selfsharpening capability of the grinding disc and allows the surface roughness to remain at a lower level compared with the turning.

\begin{tabular}{|l|c|c|}
\hline \multirow{2}{*}{ Machining Methods } & \multicolumn{2}{|c|}{ A tibial component machining times } \\
\cline { 2 - 3 } & Rough & Finish \\
\hline Turning & 25 & 20 \\
\hline Turning-grinding & 4 & 3 \\
\hline
\end{tabular}

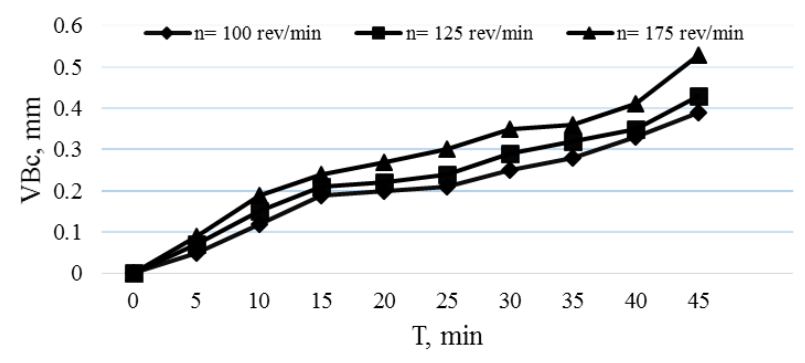

Fig. 7. Tool wear as a function of cutting time of CoCrMo alloy and tool rotation speed

\subsection{Surface defects}

The workpiece is exposed to thermal, mechanical and chemical effects during chip removal process. This situation can cause the material to strain aging and recrystallization. Strain aging causes the material gets harder but it becomes less ductile. Contrary, recrystallization makes the material softer yet more ductile. These thermal and mechanical effects are the main reasons of microstructural changes, phase transformation and plastic deformation of the material [13].

In this section, the effect of CoCrMo alloy machining on the surface defects for both methods was investigated. There are many forms of surface defects reported in the literature. Especially, high tool wear, high cutting force and high hardness of the material cause the increase in machining temperature, so the surface defects rise [14]. Machining marks, metal debris, smeared material, tearing, and white layer are commonly observed surface defects.

SEM micrographs obtained from the CoCrMo alloy sample after chip are shown in Fig. 8. Machining mark defects are observed on the surface all machined samples (Fig. 8 a). Feed marks indicated in the surface micrographs are the natural consequence of the tool feed. Feed marks are effective in machining, but their severity increases depending on increasing of feed rate. High cutting speed 
$(0.1 \mathrm{~mm} / \mathrm{rev}-175 \mathrm{rev} / \mathrm{min})$ in the turning accelerated wear on the free surface of the tool as shown in Fig. $8 \mathrm{~b}$ and led to significant feed marks on the machined surface, Fig. 8 a. When Fig. 8 b is examined, it can be seen that both the chip surface and the free surface are subjected to intense wear.

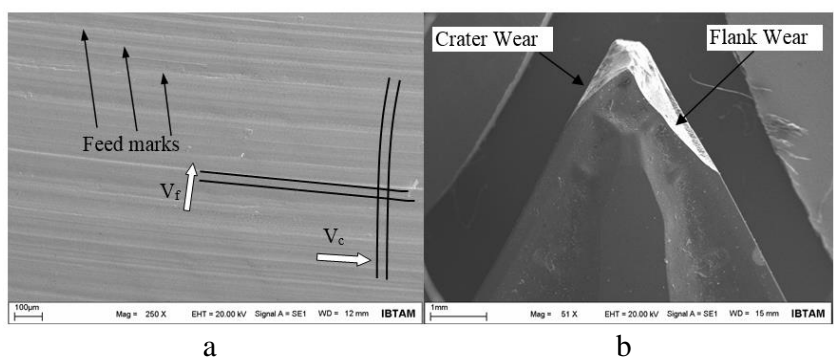

Fig. 8. The SEM micrography of marks in the CoCrMo alloy forming after chip removal: $a$-the turning at $0.09 \mathrm{~mm} / \mathrm{rev}-150 \mathrm{rev} / \mathrm{min}$; $\mathrm{b}$-wear on the cutting tool after turning at $0.1 \mathrm{~mm} / \mathrm{rev}-175 \mathrm{rev} / \mathrm{min}$

Machining marks were formed in the turning-grinding method are similar with the ones occurred in turning method as seen in Fig. 9. Irregular geometry of the grinding wheel grains causes to change the angle of the chip and gap during cutting, resulting in marks to take shapes in different directions. This causes the formation of machining marks on the surface in the direction of the geometrical shapes of the grinding wheel grain in the machined surface (Fig. 9).

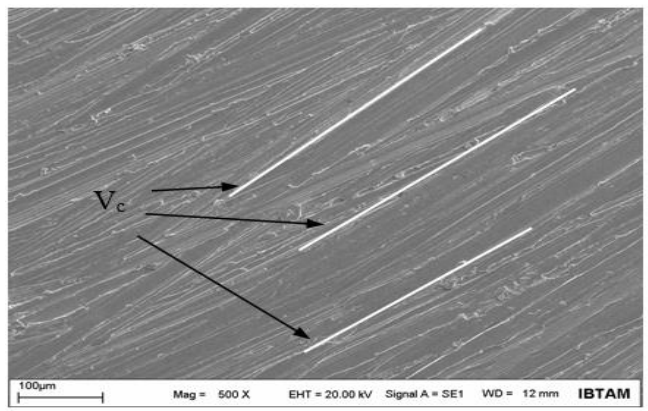

Fig. 9. The SEM micrograph of marks occurred in the turninggrinding method at $0.1 \mathrm{~mm} / \mathrm{rev}-8500 \mathrm{rev} / \mathrm{min}$

In fact, it was reported in the literature that there were feed marks on the surface even at low feed rates in the grinding process [15]. Fig. 9 is examined; it is noticed that the marks are not uniform shape as in the turning process. It has been determined that marks formed with the feed, have non-uniform shapes due to the geometry of the grinding wheel and that caused the intertwining of traces.

It is also observed that the increase in the cutting speed causes to the increase of chip particles at the micro scale on the surface (Fig. 10 a). The cutting speed values also affect the size of the chip particles in the micro-scale. Increasing the depth of cut also causes material smearing, micro-tears on the surface, plucking and notches (Fig. $10 \mathrm{~b}$ ).

Smearing of the workpiece material occurs in long machining time, and the feed marks become sharp and more clear as shown in Fig. 11. The smearing can affect the flow direction of chip under the squeezing action between the flank face and the machined surface when the tool moves along the feed direction. When Fig. 11 a is examined, the smeared material can be identified as in the shape of parallel scars along the feed direction.

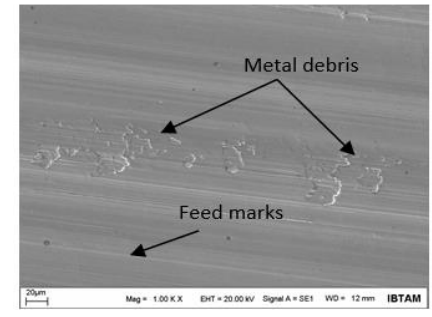

a



b
Fig. 10. The SEM micrography showing the surface defects forming in the turning of CoCrMo ally sample: $\mathrm{a}-0.08 \mathrm{~mm} / \mathrm{rev}-100 \mathrm{rev} / \mathrm{min}$;

$\mathrm{b}-0.1 \mathrm{~mm} / \mathrm{rev}-100 \mathrm{rev} / \mathrm{min}$

The non-uniform geometry of the grinding wheel particles in the turning-grinding method causes to appear of non-parallel lines as shown in Fig. 11 b. Marks also depend on the distribution of the abrasive grain on the surface. A better surface finish is provided by small abrasive grain size, dense structure, and a closer spacing between grains [10].





Fig. 11. The SEM micrography of smeared material after chip removal process of CoCrMo alloy sample: $\mathrm{a}$-the turning; $\mathrm{b}$-the turning-grinding

Microvoids and microcracks at random and irregular sizes are seen on the machined surface (Fig. $12 \mathrm{a}$ ). Microvoids and microcracks on the surface and BUE (Built up Edge) are associated with the particles broken from cutting tool and carbide particles in the workpiece. The carbide particles in the material, a small part of the cutting tool, and BUE are harder than the workpiece material, and these hard particles cannot be deformed at the plasticized layer. Hence, these particles are removed from the machined surface due to the stresses that occur during the cutting process, thus leaving the chip and creates microvoids and microcracks on the machined surface $[16,17]$.

In the turning-grinding method, it is observed that microvoids and microcracks do not occur but microchannels are formed instead (Fig. 12 b). It is considered that micro-channels are formed due to the overlapping of the plastic deformations which are formed by the particles and chip removal at the same time.

After polishing, micro-channels gradually decreased which were formed as a result of the turning-grinding method, but instead, micro voids were formed in a small amount, but the micro pores formed by the turning method still remained (Fig. 13). This is a negative situation for the tibial component. The micro-pores were found to affect the mechanical properties of the workpiece in the subsequent chip removal, oxidation and infections in the medical field, forming of micro cracks and deterioration of structural integrity $[16,18]$. 


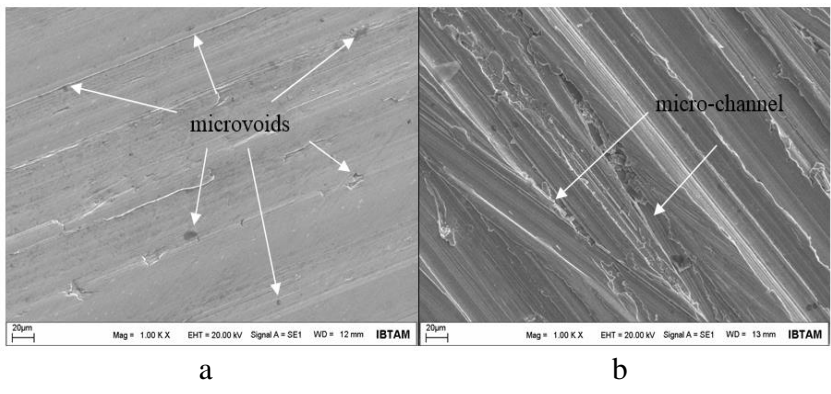

Fig. 12. SEM micrographs showing of the CoCrMo alloy sample surfaces after machining chip removal: a-the turning method; $\mathrm{b}$ - the turning-grinding method

It is observed from Fig. $13 \mathrm{~b}$ that the marks of microchannel and the sizes of the void decrease. This may due to the fact that the cutting face of the tool holder is in continuous contact with the workpiece, which affects the stability of cutting vibration caused by the wear. In the turning grinding method, the cutting particles can be regenerated themselves at all time after abrasion. Additionally, it is seen that micro cavity and cracks occur randomly in both methods. Formation of excessive density of pores and cavities might cause infections developing with time which increase the wear [19].


Fig. 13. The optical micrographs showing the machined surface of CoCrMo alloy sample after polishing: $a-$ the turning method; $b$ - the turning-grinding method

It is known in the literature that the white line formation as a result of machining of hard materials occur during turning and turning-grinding methods of CoCrMo tibia component (Fig. 14). This may be due to the high temperature generated during plastic deformation and increase of friction after free surface wear. The white layer line thicknesses are found to be in $6-12 \mu \mathrm{m}$ range in the turning, while in the turning-grinding it is found in the range of $1.3-2 \mu \mathrm{m}$. The white layer and feed marks were formed as parallel lines in the direction of cutting speed in the turning method, while in the turning-grinding method, these marks were observed in the direction of cutting speed but not in the parallel shapes as in turning. It was seen that the marks of the white layer formed in the direction of the cutting speed in the grinding, but not in the parallel shapes as in the turning. The reason is the heat generated by the friction during the removal of the chips. The heat released after the friction rises to austenitization temperature on the surface of the CoCrMo layer and then rapidly cools due to the diffusion of heat over the material [20]. These thermal effects are sometimes large enough to cause a microstructural change where the fast cooling transforms the austenite to martensite. This new phase is present only in a very small zone and can be observed with optical microscope as a very fine white layer with ultrafine grained or nanocrystalline structures [21]. Studies have also indicated that white layers affect fatigue life, corrosion resistance, wear characteristics, and causes failures because of forming different mechanical properties [22, 23].


Fig. 14. The SEM micrographs showing the white layer marks of CoCrMo alloy after chip removal process: a - the turning method; $b$ - the turning-grinding method

Temperature distribution on the tool-chip interface in the turning process of CoCrMo material is analyzed by using the finite element analysis (Fig. 15). The temperature change was obtained based on the cutting speeds used in the experiments. The cutting temperature was calculated as high as about $870{ }^{\circ} \mathrm{C}$ with the increase in revolution and feed rate. It is known that that temperature level is above of the transformation line to austenite that occur in CoCrMo [20].

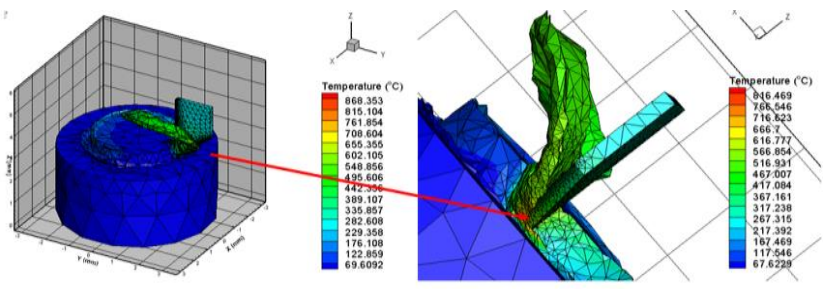

Fig. 15. The FEA results showing the temperature distribution at the tool-chip interface in turning process of CoCrMo sample

This high temperature can cause diffusion between tool and workpiece surfaces. It was determined that metal diffusion occurred between tool and workpiece upon EDX analysis obtained on CoCrMo surface after machining (Fig. 16).

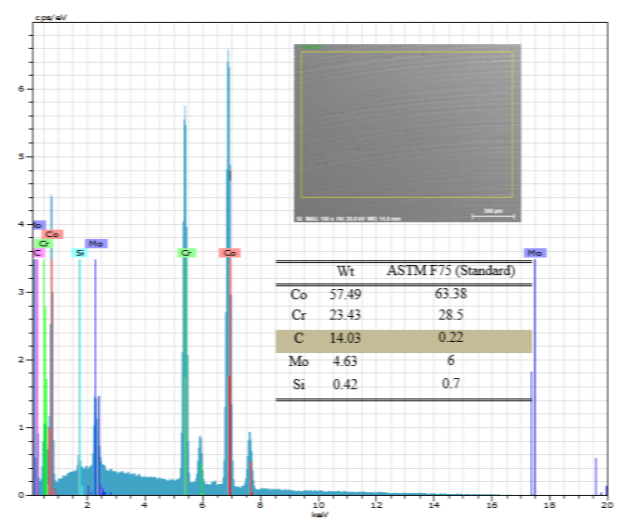

Fig. 16. The EDX spectrum of CoCrMo alloy after machining

It was seen that decrease in the ratio of $\mathrm{Co}, \mathrm{Cr}, \mathrm{Si}$, and Mo but increase in the ratio of $\mathrm{C}$ according to local EDX analysis results taken from the tibial component surface. The reason for is the temperature rises up to 
$700-900{ }^{\circ} \mathrm{C}$ during machining and causes metal diffusion. The diffusion of these heavy metals can cause toxic effects on the patient over the years.

\subsection{Microhardness}

Micro hardness of CoCrMo alloy sample was varied based on the machining parameters and machining method, and the changes in micro-hardness after turning method are given in Fig. 17.
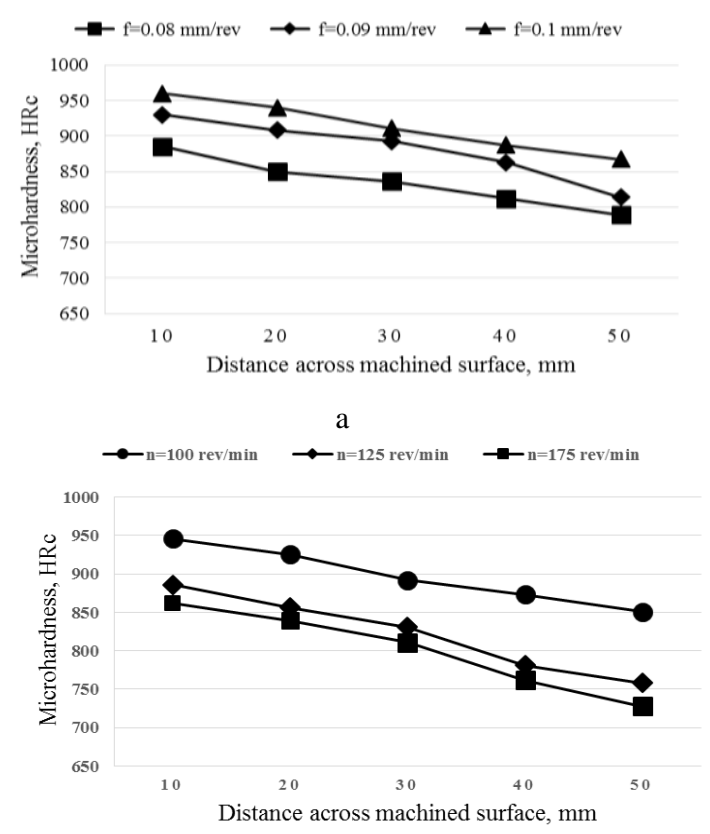

b

Fig. 17. Change of micro hardness value after turning of CoCrMo alloy: a-according to the change of feed rate; $\mathrm{b}$ - according to change of revolution

The hardness value of CoCrMo alloy increased from 350-400 HRC to about 825-955 HRC after machining. The micro hardness value increased with the increase of the feed rate, and the micro hardness decreased from the outer diameter to center. The hardness increased the feed rate due to the lower cutting speed and higher feed rate increasing machining pressure. The micro hardness decreased from the outer diameter to center with the increasing revolution as seen in Fig. 17 b. The contact time of the material with the cutting tool shortens due to the increase of cutting speed with increasing revolution. This reduces the size of the plastic deformation of the cutting area. In addition, the increase in cutting speed reduces the hardness of the machined surface by increasing the temperature and causing the material to soften. In order to compare the micro hardness values of the turning method with the turninggrinding method, the mean values in each region were taken and plotted in Fig. 18. The hardness values of CoCrMo alloy machined by turning-grinding method were obtained between 566 and 740 HRC. Micro hardness values obtained with turning-grinding method were lower than the ones recorded for turning method. This indicates that the turninggrinding method is less affected by plastic and thermal deformation.

The grinding wheel used in turning grinding method is made of a large number of abrasive particles, so this also facilitates the chip removal process. This situation reduces the tendency of the surface to undergo plastic deformation due to the occurrence of proper machining conditions.



Fig. 18. The change in the surface micro hardness of CoCrMo alloy sample with machining method of turning and turning-grinding

\section{CONCLUSIONS}

In this study, the surface quality of CoCrMo alloys used as the tibial component of the knee prosthesis was investigated in turning and turning-grinding methods. The main findings and conclusions taken from this study can be listed as below:

1. When two methods are compared, the surface roughness value obtained for the turning-grinding method was measured less than the value obtained for the other method in the ratio of $54 \%$. The surface roughness values have become similar after polishing process for both methods.

2. Although the polishing times are the same for both methods, the rough and finish machining times are about 7 minutes in the turning-grinding method, while these times are 45 minutes in the turning method.

3. In the turning method, one cutting tool was used for one tibial component during rough machining, while one cutting tool was used for two tibial components during finish machining.

4. Cooling fluid is used in turning method, while it is not required in the turning-grinding method.

5. A decrease in the size of micro-pores and cracks was observed with the ratio of about $64 \%$ in turninggrinding method based on measurements obtained by image processing.

6. White layer defects, feed marks, metal particle remains and smeared materials were observed in both methods.

7. The machining temperature reaches up to $900{ }^{\circ} \mathrm{C}$ during machining according to FEA analysis of turning, and phase transformation occurs at this temperature.

8. EDX analysis performed after machining showed that metal diffusion occurred.

9. It was measured that the value of micro hardness increased with the increase of the feed rate, while it decreased with the increase of the cutting speed. It was also measured that the micro hardness decreased relatively with the ratio of about $31 \%$ in the turninggrinding method.

As a result of this new developed method, manufacturing costs have been reduced due to the use of only one turning lathe. So, the machining of more CoCrMo tibial alloy has been performed with one cutting tool in accordance with ASTM F75 standards [24]. 


\section{Acknowledgements}

This research was supported by OTIMED Medical Company and Ordu University (Project number: AR-1661).

\section{REFERENCES}

1. Bordin, A., Ghiotti, A., Bruschi, S. Machinability Characteristics of Wrought and EBM CoCrMo Alloys HPC14 2014: pp. 89-94.

https://doi.org/10.1016/j.procir.2014.03.082

2. Bordin, A., Bruschi, S., Ghiotti, A. The Effect of Cutting Speed and Feed Rate on the Surface Integrity in Dry Turning of CoCrMo Alloy 2nd CIRP CSI 13 2014: pp. 219-222. https://doi.org/10.1016/j.procir.2014.04.038

3. Karpuschewskia, B., Döringa, J. Influence of the Tool Geometry on the Machining of Cobalt Chromium Femoral Heads Procedia CIRP 49 2016: pp. 67-71. https://doi.org/10.1016/j.procir.2015.07.034

4. Shokrani, A., Dhokia, V., Newman, S.T. Cryogenic High Speed Machining of Cobalt Chromium Alloy 7th HPC 46 2016: pp. 404-407. https://doi.org/10.1016/j.procir.2016.04.045

5. Song, Y.C., Park, C.H. Moriwaki, T. Mirror Finishing of Co-Cr-Mo Alloy Using Elliptical Vibration Cutting Precision Engineering 34 2010: pp. 784-789. https://doi.org/10.1016/j.precisioneng.2010.02.003

6. Bruschi, S., Ghiotti, A., Bordin, A. Effect of the Process Parameters on the Machinability Characteristics of a CoCrMo alloy Trans Tech Publications 2013: pp. 554-557. https://doi.org/10.4028/www.scientific.net/KEM.554-557.1976

7. Jagtap, K., Pawade, R.A. Comparative Analysis of Cutting Forces in Precision Turning of Co-Cr-Mo Bio-implant Alloy in Dry and Wet Machining Environments Advances in Intelligent Systems Research 137 2016: pp. 234-241.

8. Akhtar, W., Sun, J., Chen, W. Effect of Machining Parameters on Surface Integrity in High Speed Milling of Super Alloy GH4169/Inconel 718 Material Manufacture Processes 31 2016: pp. 620-627. https://doi.org/10.1080/10426914.2014.994769

9. Ulutan, D., Özel, T. Machining Induced Surface Integrity in Titanium and Nickel Alloys: A Review International Journal of Machine Tools \& Manufacture 51 2011: pp. 250-280. https://doi.org/10.1016/j.ijmachtools.2010.11.003

10. Abdel, H., El-Hofy, G. Fundamentals of Machining Processes 2nd ed. Taylor \& Francis, New York, 2014: pp. 236-237.

11. Malkin, S., Guo, C. Grinding Technology, 2nd ed. Industrial Press. New York, 2008: pp. 150-153.

12. Marinov, V. Manufacturing Processes for Metal Products, 1nd ed., Kendall Hunt Publishing, Iowa, 2011: pp. $77-80$.

13. Yang, X., Liu, C.R. Machining Titanium and Its Alloys Machining Science and Technology: An International
Journal 3 1999: pp. 107-139.

https://doi.org/10.1080/10940349908945686

14. Ginting, A., Nouari, M. Surface Integrity of Dry Machined Titanium Alloys International Journal of Machine Tools \& Manufacture 49 2009: pp. 325-332.

https://doi.org/10.1016/j.ijmachtools.2008.10.011

15. Demir, H., Güllü, A. An Investigation into the Influences of Grinding Wheel Hardness and Grinding Parameters on Surface Roughness and Grinding Forces Journal of the Faculty of Engineering and Architecture of Gazi University 23 (3) 2008: pp. $577-584$.

16. Xue, C., Chen, W.Y. Surface Damages Generated in Hole Making of a Cast Nickel-Based Alloy Material Science Forum 2012: pp. 57-60. https://doi.org/10.4028/www.scientific.net/MSF.697-698.57

17. Chen, L., El-Wardany, T.I. Harris, W.C. Modeling the Effects of Flank Wear Land and Chip Formation on Residual Stresses CIRP Ann Manufturing Technology 53 2004: pp. 95-98.

18. Jaharah, A.G., Hassan, C., Muhamad, N. Machined Surface of AISI H13 Tools Steels When and Milling Using P10 TiN Coated Carbide Tools European Journal of Science Research 26 2009: pp. 247-254. https://doi.org/10.1016/j.jmatprotec.2004.04.353

19. Gallo, J., Holinka, M., Moucha, C. S. Antibacterial Surface Treatment for Orthopaedic Implants International Journal of Molecular Sciences 15 2014: pp. 849-880. https://doi.org/10.3390/ijms150813849

20. Zhang, M., Yang, Y., Song, C. An Investigation into the Aging Behavior of CoCrMo Alloys Fabricated by Selective Laser Melting Journal of Alloys and Compounds 750 2018: pp. $878-886$. https://doi.org/10.1016/j.jallcom.2018.04.054

21. Che-Haron, C.H., Jawaid, A. The Effect of Machining on Surface Integrity of Titanium Journal of Materials Processing Technology 166 2005: pp. 188-192. https://doi.org/10.1016/j.jmatprotec.2004.08.012

22. Bartha, B.B. Zawadzki, J., Chandrasekar, S. Wear of Hard-Turned AISI52100 Steel Metallurgial and Materials Transactions 36 2005: pp. 1417-1425. https://doi.org/10.1177/0954406211424865

23. Bosheh, S.S., Mativenga, P.T. White Layer Formation in Hard Turning of H13 Tool Steel at High Cutting Speeds Using CBN Tooling International Journal of Machine Tools \& Manufacture 46 2006: pp. 225-233. https://doi.org/10.1016/j.ijmachtools.2005.04.0

24. Chiba, A., Kumagai, K., Nomura, N., Miyakawa, S. Pinon-disk Wear Behavior in a Like-on-like Configuration in a Biological Environment of High Carbon Cast and Low Carbon Forged Co-29Cr-6Mo Alloys Acta Materialia 55 (4) 2007: pp. 1309-1318. https://doi.org/10.1016/j.actamat.2006.10.005 